\title{
Understanding the mobility of potential nutrients in rock mining by-products: An opportunity for more sustainable agriculture and mining
}

Adilson Celimar Dalmora; Claudete Gindri Ramos; Leandro Gomez Plata; Marcondes Lima da Costa; Rubens Muller Kautzmann; Luis Felipe Silva Oliveira

\begin{abstract}
The increase in demand for highly soluble fertilizers brings a global sustainability concern. Alternative sources for traditional fertilization are therefore needed. Rock powder use has been proposed as an alternative approach to soil remineralization. However, research on the agricultural potential of minerals and rocks as alternative sources of nutrients is limited to changes in soil chemical attributes or effects on crop yield. In this work, we report an experimental study addressing the dissolution of two silicate rock-derived powders (andesite and dacite) that were produced during mining activities in Southern Brazil. The rock powders were exposed to Milli-Q water at $\mathrm{pH}$ (7.4-8.8) range, in solutions of $0.1 \mathrm{~mol} \mathrm{~L}^{-1}$ citric acid at $\mathrm{pH}$ range $2.1-3.3$, and Milli-Q water acidified with $0.5 \mathrm{~mol} \mathrm{l}^{-1}$ acetic acid ( $\mathrm{pH} 5^{-5.8}$ ), in a continuous mechanical rotatory shaker at room temperature. Dissolution kinetics were determined as a function of reaction times at 24 to $5760 \mathrm{~h}$, and solution $\mathrm{pH}$. Based on this kinetics, dissolution rates were determined for the individual powders and compared to expected values for aluminosilicates. Based on this comparison, it was shown that the application of andesite and dacite rockderived powder to replace high soluble fertilizers is feasible due to high dissolution rates of their minerals. The average andesite dissolution rates in Milli-Q water, in citric acid solution, and in Milli-Q water acidified with acetic acid were $2.1 \times 10^{-5}, 1.92 \times 10^{-1}$ and $6.3 \times 10^{-4} \mathrm{mmol} \mathrm{cm}^{-2} \mathrm{~S}^{-1}$, respectively for $\mathrm{Ca}$, being $183 \%, 22.6 \%$, and $69.2 \%$ higher than for the dacite rock. This make andesite rock a potential substitute for carbonatebased liming. In contrast, the average dacite dissolution rates in Milli-Q water, in citric acid solution, and in Milli-Q water acidified with acetic
\end{abstract}


acid were $1.05 \times 10^{-} 5,7.22 \times 10^{-5}$, and $3.72 \times 10^{-5} \mathrm{mmol} \mathrm{cm}^{-2} \mathrm{~S}^{-1}$, respectively for $\mathrm{K}$, being $72.0 \%, 61.4 \%$, and $73.6 \%$ higher than the andesite rock. This highlights its potential use as a K source for agriculture to replace highly soluble K-fertilizers.

\section{Keywords}

Mineral dissolution; Silicate rocks; Andesite; Dacite; Multi-nutrients source; Sustainable agricultura; Dissolution kinetics. 